Kansas State University Libraries

New Prairie Press

\title{
USING TIME-SERIES INTERVENTION ANALYSIS TO MODEL COW HEART RATE AFFECTED BY PROGRAMMED AUDIO AND ENVIRONMENTAL/PHYSIOLOGICAL CUES
}

\author{
Dean M. Anderson \\ Norbert Remenyi \\ Leigh W. Murray
}

Follow this and additional works at: https://newprairiepress.org/agstatconference

Part of the Agriculture Commons, and the Applied Statistics Commons

\section{c) (i) (9)}

This work is licensed under a Creative Commons Attribution-Noncommercial-No Derivative Works 4.0 License.

\section{Recommended Citation}

Anderson, Dean M.; Remenyi, Norbert; and Murray, Leigh W. (2010). "USING TIME-SERIES INTERVENTION ANALYSIS TO MODEL COW HEART RATE AFFECTED BY PROGRAMMED AUDIO AND ENVIRONMENTAL/ PHYSIOLOGICAL CUES," Conference on Applied Statistics in Agriculture. https://doi.org/10.4148/ 2475-7772.1063

This is brought to you for free and open access by the Conferences at New Prairie Press. It has been accepted for inclusion in Conference on Applied Statistics in Agriculture by an authorized administrator of New Prairie Press. For more information, please contact cads@k-state.edu. 


\title{
Using Time-series Intervention Analysis to Model Cow Heart Rate Affected by Programmed Audio and Environmental/Physiological Cues
}

\author{
Dean M. Anderson ${ }^{\mathrm{a}}$, Norbert Remenyi ${ }^{\mathrm{b}}$, and Leigh W. Murray ${ }^{\mathrm{c}}$ \\ ${ }^{a} U . S$. Department of Agriculture, Agriculture Research Service, Jornada Experimental \\ Range,Box 3003, MSC 3JER, NMSU, Las Cruces, New Mexico 88003-8003, USA. \\ Correspondence: deanders@nmsu.edu; ${ }^{b}$ H. Milton Stewart School of Industrial Engineering \\ and Systems Engineering, Georgia Tech, Atlanta, GA 30332-0205; 'Department. of Statistics, \\ Kansas State University, Manhattan, KS 56606, USA, formerly University Statistics Center, New \\ Mexico State University, Las Cruces, New Mexico 88003, USA
}

\begin{abstract}
This research is the first use of Box-Jenkins time-series models to describe changes in heart rate (HR) of free-ranging crossbred cows (Bos taurus) receiving both programmed audio cues from directional virtual fencing $\left(\mathrm{DVF}^{\mathrm{TM}}\right)$ devices and non-programmed environmental/physiological cues. The $\mathrm{DVF}^{\mathrm{TM}}$ device is designed to control the animal's location on the landscape. Polar Accurex ${ }^{\circledR}$ devices were used to capture HR every minute between 19 and 24 March 2003, when three mature free-ranging beef cows, previously habituated to the $\mathrm{DVF}^{\mathrm{TM}}$ device, were confined to a brush-infested area of an arid rangeland paddock. Global positioning system (GPS) electronics were used to record each cow's location approximately every minute while it was in a 58 ha virtual paddock ( $\mathrm{VP}^{\mathrm{TM}}$ ) and every second when it penetrated a virtual boundary ( $\mathrm{VB}^{\mathrm{TM}}$ ). The cows never escaped through the $\mathrm{VB}^{\mathrm{TM}}$, although they penetrated it a total of 26 times in 11 different events, at which times they received programmed audio cues lasting from 1 to $56 \mathrm{~s}$. Plots of these data reveal that HR spikes from programmed audio cues all fell within textbook range for cow HR (40-186 beats per minute, bpm). Heart rate spikes were analyzed using BoxJenkins intervention analysis models, which showed that for both audio and selected environmental/physiological events, HR spikes typically returned to pre-cuing "baseline" levels in about one minute. However, the longest return-time to baseline (about four minutes) was for an environmental/physiological event of unknown origin. HR, animal location, weather and other electronic data should be measured at equally-spaced time intervals using a single time stamp to accurately associate HR changes with possible causes.
\end{abstract}

Keywords: time-series analysis; Polar ${ }^{\circledR}$ heart rate monitors; free-ranging crossbred beef cattle; audio cues; directional virtual fencing (DVFTM)

\section{INTRODUCTION}

Animal heart rate (HR) may be suitable for evaluating stress associated with husbandry practices, external environmental challenges, food depravation, and energy expenditure (Richards and Lawrence 1984; McGuirk et al. 1990; Lay et al. 1992; Hopster and Blokhuis 1994; Hagen et al. 2005; Brosh et al. 2006; Brosh 2007). One of the most recent uses of HR has been as an indicator of the welfare of dairy cows (Hagen et al. 2005; Gygax et al. 2008). All husbandry 
involves some level of stress that can impact animal physiology in a number of ways (Cook \& Jacobson 1996). Heart rate ( Porges 1985; Hopster and Blokhuis 1994) and heart rate variability (HRV; Hagen et al. 2005; von Borell et al. 2007) are relatively recent and reliable physiological indicators used to monitor stress in cows. Cattle HR ranges between 40 and 70 beats per minute (bpm) at rest (Anonymous 1986), while Rometsch and Becker (1993) reported the standing HR of Simmental cattle to range between 54 and 62 bpm, with a peak HR during exercise of 186 bpm. Various equipment has been used to monitor livestock HR (Baldock and Sibly 1990; Besch et al. 1992;Palestrini et al. 1998), including electronic devices used by sportsmen and athletes (Janžekovič et al. 2006).

Animal control remains a major aspect of free-ranging animal husbandry. Undoubtedly herding was man's first method for controlling animals (Instinct Displayed, Letter 34, page 6. in Youatt 1836) and remains a major means of control in third world countries in the $21^{\text {st }}$ century (Robinett and Bedunah. 2008). Barbed wire fences resulting from Joseph Glidden's 1874 barbed wire patent has changed the face of free-ranging animal production throughout much of today's world (McCallum and McCallum, 1965; Buckhouse and Winward 1976). Recently a new form of animal control known as virtual fencing (Anderson, 2007) has been developed that uses GPS technology and audio or electrical cues to control an animal's movements. To date, research specifically addressing the effect of audio and electrical stimulation from virtual fencing devices on cattle has not been conducted, yet it is known that sound (Arnold et al. 2007) and electric current (Gorewit and Scott 1986) have been shown to affect HR in cattle.

Although routine in principle, there are many aspects of animal control that can impart stress to an animal and these should be minimized for optimum production to be realized (Smith, 1988). Since animal welfare issues are becoming more and more pivotal in determining how animal husbandry practices are carried out (Deag 1996; Croney and Millman 2007), this research was undertaken to evaluate how stressful DVFTM cuing is, to free-ranging cattle, as measured by cow HR.

Therefore, the objective of this paper is to use time-series intervention analysis (Box and Tiao 1975; Box et al. 1994) to quantitatively model cow HR changes as functions of either programmed audio cues or non-programmed environmental/physiological events, with particular emphasis on estimating the magnitude and the duration of HR change and thereby provide insight into how DVFTM affects cow $\mathrm{HR}$ as a surrogate for stress. To the first author's knowledge, this research represents the first use of time series to model cattle HR, although it has recently been used to model HR in humans (Zakynthinaki and Stirling 2007).

\section{METHODS}

\subsection{Study site and management}

Data were collected between 19 and 24 March 2003 in Paddock 10B (Fig. 1) located on the Jornada Experimental Range (JER) in southern New Mexico at approximately $32^{\circ} 37^{\prime} \mathrm{N}, 106^{\circ}$ $45^{\prime} \mathrm{W}$. Climate details characterizing this arid rangeland (mean annual precipitation $230 \mathrm{~mm}$ ) 
have previously been described (Paulsen \& Ares 1962; Wainwright 2006). Prior vegetation sampling in Paddock 10B found that grasses (39\% and 46\%), forbs (36\% and 49\%) and shrubs (14\% and 19\%) composed the mosaic pattern of the standing crop (Hulet et al. 1982; Anderson et al. 1985). The paddock's topography is relatively flat and is composed of three major landforms at an elevation approximately $1260 \mathrm{~m}$ above sea level (Monger 2006). Paddock $10 \mathrm{~B}$ is approximately square (Fig. 1; 466 ha), with a single source of drinking water located inside a corral in the south-east corner. The virtual paddock (VP ${ }^{\mathrm{TM}}$, indicated as Zone 1 in Fig. 1 ) was a 58 ha sub-area bordered by a virtual boundary $\left(\mathrm{VB}^{\mathrm{TM}}\right)$ to its north, which was a $200 \mathrm{~m}$ wide zone in which cows would receive sensory cues if they attempted to leave the VPTM. There were four potential levels of cuing severity to which the free-ranging cows could have been exposed (Fig. 1 ). The center of the $\mathrm{VB}^{\mathrm{TM}}$, called the virtual center line $\left(\mathrm{VCL}^{\mathrm{TM}}\right)$, served as a reference line for the directional virtual fencing (DVFTM) system and indicates where a conventional fence would have been constructed. For a more detailed description of how DVFTM operates see Anderson (2007).

\subsection{Animals and devices}

Three mature ( $\geq 9$ years of age) cross-bred beef cows were equipped with $\mathrm{DVF}^{\mathrm{TM}}$ devices (Anderson \& Hale 2001; Rango et al. 2003; Anderson 2007) carried on the head/neck region of their body.. Global positioning system (GPS) hardware and software recorded where the cow was on the landscape approximately every minute while it was in the VPTM and every second once the cow penetrated into the $\mathrm{VB}^{\mathrm{TM}}$. These data were continuously compared to how far the cow was from the VCL ${ }^{\mathrm{TM}}$ forming the center of the $\mathrm{VB}^{\mathrm{TM}}$. This comparison was accomplished using data defining the VCL ${ }^{\mathrm{TM}}$ stored in the DVF ${ }^{\mathrm{TM}}$ device's geographical information system (GIS) software. Based on this comparison, once the animal was determined to have penetrated the $\mathrm{VB}^{\mathrm{TM}}$, the DVF ${ }^{\mathrm{TM}}$ device's magnetometer determined the angle of the cow's forward trajectory towards the VCL ${ }^{\mathrm{TM}}$. This angle determined to which side of the animal the autonomous programmed modulated audio cue(s) would be administered in order to attempt to return the cow to the VPTM in the shortest time and with the least amount of cuing (stress). Audio cues administered to the right ear were different from those administered to the left ear. Between 19 and 24 March, none of the cows penetrated further than $18 \mathrm{~m}$ into the VB ${ }^{\mathrm{TM}}$, with most of the penetration distances being around $10 \mathrm{~m}$. Thus the cows were only exposed to programmed audio cues. The cows had previously been habituated to DVFTM control for at least 2 years prior to this study which included their experiencing programmed electrical stimulation. The cows' prior experience with DVFTM control may provide one explanation as to why they did not penetrate far enough into the $\mathrm{VB}^{\mathrm{TM}}$ during this five-day period to receive both audio and electrical stimulation cues.

In addition to the $\mathrm{DVF}^{\mathrm{TM}}$ hardware, each cow was equipped with a Polar ${ }^{\circledR}$ Accurex Plus HR Monitor (Polar Electro Oy; Kempele, Finland) set to collect data every 60 s. The monitor was affixed to a girth strap behind the front legs of the animal. This girth strap was similar to the design used by Hopster and Blokhuis (1994), but differed from theirs by having a wider strap $(\approx$ $11 \mathrm{~cm}$ ) with some elasticity, provided by adding a section of auto inner-tube material on one end of the strap next to the plastic buckle. This insured constant contact of the electrodes with the 
cow's body as gut fill changed, yet prevented pressure necroses. An absorbent horse-hair rug pad was placed directly over the cow's back to prevent the girth strap from abrading the skin as a result of the rubbing motion of the strap on the cow's backbone as she walked. The electrodes were taped to the girth strap to insure they did not move out from under the strap once it was in place on the cow's body. Furthermore, to help insure contact of the electrodes with the cow's skin, hair was clipped over the area where the electrodes contacted the animal's body and a salt $(\mathrm{NaCl})$ paste was applied to the electrode area before the girth belt was tightened around the cow. This protocol helped insure continuous capture of the HR signal. Because of memorystorage limitations and power requirements, the location data from the $\mathrm{DVF}^{\mathrm{TM}}$ devices and the HR monitors were only taken at one-minute intervals and were downloaded into a laptop computer every Monday, Wednesday and Friday. At these times, the cows and equipment were evaluated for physical damage and if none was observed, the electronic equipment and batteries were taken off the animals, serviced as required and then replaced on the animals and the reinstrumented animals were again released into the paddock.

\subsection{Data set preparation}

The Quattro Pro (.qpw) data files for location (GPS) and tab-separated text files (.txt) for HR were converted to comma separated text, (.csv) for processing in SAS ${ }^{\circledR}$ software (SAS Institute 1999). Data for location and/or date that contained invalid (missing, zero or out of range) values were deleted $\left(<0.3 \%\right.$ of the data), then location and HR data sets were merged in SAS ${ }^{\circledR}$ (SAS Institute 1999). This produced a data set in which lines contained location as well as HR for each non-missing minute. The $60 \mathrm{~s}$ sequence at which HR was recorded was determined based on an initial time stamp that was entered when the device was powered-up. All subsequent time was determined based on the summation of cumulative $60 \mathrm{~s}$ intervals. In contrast, the GPS data were recorded at approximately a $43 \mathrm{~s}$ to $53 \mathrm{~s}$ rate while the cow was in the $\mathrm{VP}^{\mathrm{TM}}$. However, once the cow entered the VB ${ }^{\mathrm{TM}}$, at the very next GPS reading recorded, the DVFTM device began recording location data every second. These two different recording-rate protocols produced disjoint data sets that were merged to match GPS and HR measurements made within the same minute. In the case of multiple GPS measurements per minute, the location record closest to the HR record in seconds was used to minimize the discrepancy between the two readings. This approach was deemed appropriate since the actual lag between when a cue was administered to a cow and when it was reflected in a change in the cow's HR has been found to be almost immediate (Lefcourt et al. 1986).

All HR changes related to audio cues (i.e., when the GPS location indicated that the cow had entered the $\mathrm{VB}^{\mathrm{TM}}$ ) were increases and were all modeled by time series intervention models. Increases in cow HR evaluated when cows were not inside the VB ${ }^{\mathrm{TM}}$ (i.e., non-cueing events) were chosen in a non-random manner to reflect patterns similar to those modeled while the cows were inside the $\mathrm{VB}^{\mathrm{TM}}$. In general, the set of HR changes for non-cueing events chosen for modeling were increases of at least $15 \mathrm{bpm}$ above baseline (pre-event) levels. Such HR increases are referred to here as "spikes." 
After identifying a HR "spike" (either from a cuing or non-cuing event), a block of data was selected for modeling the HR spike which began approximately sixty minutes prior to the timepoint of the event to have a sufficiently long baseline for modeling (Box et al. 1994, p.17). In addition, the end of a data block was set twenty minutes after the event, which, on analysis, proved sufficient to capture all HR activity related to an event. Once a data block was formed, data were checked to see if location and HR were present for every minute. There was never a missing line of HR data but infrequently there was a missing location, and in these cases, linear interpolation was used to estimate the missing location as the location mean of the immediate previous and following minutes. Missing locations occurred for only a total of 7 records in 3 time periods out of the total of 16 time periods that were analyzed.

\subsection{Statistical analysis}

"Time-series" is the term applied to observations that are measured sequentially in time, as well as the set of statistical techniques used to model the observed pattern of such data (Box et al. 1994). Such observations are correlated through time and therefore are not independent of each other. Autoregressive-Integrated-Moving Average models, abbreviated ARIMA $(p, d, q)$, are used to model univariate time series (i.e., one variable at a time; Box et al. 1994).

Intervention models (first introduced by Box \& Tiao 1975) are a special case of ARIMA models (Box et al. 1994) where the model contains an input (predictor) series which indicates the occurrence of a special event or environmental change occurring at a known time $T$, called an "intervention event". In this paper, the intervention event is a programmed audio cue or some environmental/physiological occurrence that may be related to a change in HR. Box et al. (1994), Vandaele (1983), Montgomery et al. (1990) and Pankratz (1991) provide an in-depth discussion of intervention analysis, but because intervention analysis has not been a statistical technique typically used in evaluating HR data, a brief discussion will be given, in terms of this specific application.

An intervention model contains two basic components: 1) the intervention component which measures the effect of the event (cue) on the univariate time series (HR); and 2) the noise series which accounts for the residual variability in the observed HR data when the effect of the cue has been modeled. Therefore, the general form of an intervention model Box \& Tiao (1975) for HR at time $t\left(y_{t}\right)$ is:

$$
y_{t}=\frac{\omega(B) B^{b}}{\delta(B)} \xi_{t}+N_{t}, t=1,2, \ldots, n
$$

where $B$ is the "backshift operator" in standard time-series notation (Box et al. 1994) such that $B^{b} \xi_{t}=\xi_{t-b}$. The intervention component is

$$
\frac{\omega(B) B^{b}}{\delta(B)} \xi_{t},
$$

where $\xi_{t}$ is a deterministic input series of 0's and 1's (like a dummy variable in ordinary regression), which specifies when the intervention event occurred and whether the event should 
produce a temporary or permanent change in the series. The intervention component has three possible model sub-components (Box et al. 1994). First, the term $B^{b}$ represents a time delay or backshift of $b$ time units in the model, which indicates the effect of the intervention event is apparent $b$ time units after the event occurs. If $b=0$, then the output series $y_{t}$ responds "instantaneously" to the intervention event, that is, before the next time measurement is made. The second and third model sub-components are the numerator operator, with $r+1$ parameters, $\omega_{i}$,

$$
\omega(B)=\omega_{0}-\omega_{1} B^{1}-\omega_{2} B^{2} \ldots-\omega_{r} B^{r}
$$

and the denominator operator, with $s$ parameters, $\delta_{j}$,

$$
\delta(B)=1-\delta_{1} B^{1}-\delta_{2} B^{2} \ldots-\delta_{s} B^{s} .
$$

The presence of a denominator operator (4) indicates whether or not the process returns to baseline (i.e., pre-event) levels gradually or not. If there is not a damping operator in the intervention component, then HR is returning to baseline "abruptly" (at least at the scale of oneminute measurements). However, if there is a damping operator, HR is gradually returning to baseline. The relationships between the occurrence and form of a numerator operator and/or a denominator operator in the intervention component and the form of the observed HR spike will be discussed below in more detail for specific examples.

Intervention models can be generalized to have more than one intervention component (just like a regression model can have more than one predictor). For example, for the case where two intervention events (e.g., two audio cues to the cow) occur in a brief period of time (approximately 30 minutes or less), the intervention model would be

$$
y_{t}=\frac{\omega_{1}(B) B^{b_{1}}}{\delta_{1}(B)} \xi_{1 t}+\frac{\omega_{2}(B) B^{b_{2}}}{\delta_{2}(B)} \xi_{2 t}+N_{t}, t=1,2, \ldots, n
$$

where the two $\omega(B)$ and $\delta(B)$ operators are defined as in (3) and (4), and can have different forms for the two interventions (cues or environmental events). Clearly this can be generalized to intervention models with more than two intervention components.

The noise component $N_{t}$ is typically modeled as an ARIMA ( $\left.p, d, q\right)$ model (Box et al. 1994), which has standard form

$$
\varphi(B)(1-B)^{d} N_{t}=\theta(B) a_{t},
$$

where the residuals $a_{t}$ are assumed to be a "white noise process", that is, they are independently and identically distributed $N\left(0, \sigma_{a}^{2}\right)$, where $\sigma_{a}^{2}$ is constant over time (Box et al. 1994). In addition, the non-seasonal difference operator for a nonstationary homogeneous time series is

$$
(1-B)^{d}
$$


the general autoregressive operator, with $p$ autoregressive parameters, $\phi_{i}$, is

$$
\varphi(B)=(1-B)^{d}\left(1-\phi_{1} B-\phi_{2} B^{2} \ldots-\phi_{p} B^{p}\right)
$$

and the moving average operator, with $q$ moving average parameters, $\theta_{j}$, is

$$
\theta(B)=1-\theta_{1} B-\theta_{2} B^{2} \ldots-\theta_{q} B^{q} .
$$

Two common forms of the deterministic input series, $\xi_{t}$, are the step and pulse functions (Box et al. 1994). The step function is typically used to model an intervention event which is expected to result in a permanent effect after time $T$ and so is not appropriate for these HR data. The pulse function is typically used to model an intervention event which is expected to have a temporary change, like the effect of programmed audio cues or non-programmed environmental/ physiological events on HR. In the case of multiple events that are close together in time, a set of pulse functions are used, one for each event and the overall intervention component is the sum of the individual event components. For more information on intervention models with multiple events, see Box et al. (1994).

The general form of the pulse function for an event occurring at time $T$ is

$$
P_{t}^{(T)}=\left\{\begin{array}{ll}
0, & t \neq T \\
1, & t=T
\end{array},\right.
$$

so there is only one "1", at time $T$, the time point when the intervention event occurred. Therefore, the intervention component (2) to model a temporary effect for these HR data will be

$$
\frac{\omega(B) B^{b}}{\delta(B)} P_{t}^{(T)}=\frac{\omega(B)}{\delta(B)} P_{t-b}^{(T)}
$$

for $T$ the known time point of an event.

The steps in fitting an intervention model (Box et al. 1994, outlined below) are similar to those in ordinary ARIMA models, with the addition of the preliminary identification of the form of the intervention component. The form of the intervention component of the model (10) can be frequently predicted by an understanding of the mechanism and possible effect of the intervention (Box et al. 1994). Identification can also be helped by direct inspection of a timeplot of the data.

Commonly seen examples of intervention models and their related (theoretical) timeplots (e.g., plot of HR versus time) can be found in Box et al. (1994) and Vandaele (1983), among others. In these examples, it can be seen that if a denominator function $\delta(B)$ is in the intervention component, then the effect of the event damps out exponentially, so that HR gradually returns to "normal". Without the denominator term, the effect cuts off after the highest time lag (i.e., exponent term of $B$ ) of numerator terms in the model, that is, HR "immediately" returns to "normal" within that number of time periods (minutes, in this paper).

Intervention analysis also assumes that the intervention only affects the mean of the time series, so the ARIMA model with its parameters are constant before and after the intervention. This 
assumption may not hold in some cases of our identified periods of events, because unknown environmental/physiological events (e.g., HR changes when a cow has been lying down and then stands up and moves) might change the form of the ARIMA model.

Vandaele (1983) gives various strategies for the identification of the intervention component, and Pankratz (1991) especially discusses empirical techniques for building interventions models. Box et al. (1994), Vandaele (1983) and Pankratz (1991) also discuss diagnostics to check model fit. The SAS ${ }^{\circledR}$ ARIMA procedure (SAS Institute 1999; Brocklebank \& Dickey 2003) was used to perform the following steps for fitting the intervention models on an individual cow's HR data: 1) Baseline identification, estimation and diagnostic checks of a preliminary noise model fitted on the pre-event series using the sample autocorrelation and partial auto correlation functions; 2) Tentative identification of the intervention component of the model, referring back to generalized figures presented in Vandaele (1983) and examining the HR timeplot; 3) Preliminary estimation of the intervention component and tentative identification of the noise model based on the sample autocorrelation and partial autocorrelation functions of the preliminary residuals obtained from fitting only the intervention component; 4) Joint estimation of the intervention component with the noise model and model-checking and diagnostics.

Because the time-series model-building procedure is naturally an iterative process, Step 1 was only used as a guiding step in the model-fitting process, because the sample autocorrelation and partial autocorrelation functions can change for the whole time-series. Vandaele (1983) suggests first identifying and estimating the form of the intervention component, and then identifying the ARIMA noise series using the autocorrelation and partial autocorrelation functions of the residuals obtained from fitting the intervention component.

In Step 4, we estimated the intervention and noise model together and checked the model fit. The following diagnostics were checked to evaluate model fit (Box et al. 1994): 4a) Diagnostics checks on model parameters (statistical significance of all fitted parameters at $\alpha=0.1$, except as noted for good fit; stationarity and invertibility conditions for parameters of the fitted noise model; and "low" correlation between all parameter estimates, i.e., $|r|<0.5$ ); and 4-b) Diagnostics to check that fitted residuals are a "white noise process" (overall Chi-square goodness-of-fit test that autocorrelations of residuals are not significantly different from zero; test the mean of the residuals is zero (t-test); check for constant variance of residuals by examination of the timeplot of residuals.

\section{RESULTS}

Between 19 March at 0925 hours and 24 March at 2359 hours, a total of 11 audio $(A)$ and 8 environmental/physiological $(E)$ time intervals were modeled, with a total of $26 \mathrm{HR}$ spikes in $A$ events and $10 \mathrm{HR}$ spikes in $E$ events. For cow 4127 there were seven $A$ events with a total of 20 HR spikes and two $E$ events with a total of four HR spikes. Intervention models for cow 4127 are summarized in Tables 1A $(A)$ and $1 \mathrm{~B}(E)$. For cow 4130, there were three $A$ events with a total of four HR spikes and three $E$ events, each with one HR spike. Intervention models for cow 
4130 are summarized in Tables 2A $(A)$ and 2B $(E)$. For cow 4132, there was only one $A$ event with two HR spikes and three $E$ events, each with one HR spike. Intervention models for cow 4132 are summarized in Tables 3A $(A)$ and 3B $(E)$. Example timeplots for $A$ events are given in Figures 2 (cow 4127, interval A4), 3 (cow 4132, interval A1) and 4 (cow 4127, interval A3) and for one $E$ event in Figure 5 (cow 4130, interval E1).

Note that in the fitted models in Tables $2 \mathrm{~A}-4 \mathrm{~B}$, the part of the model containing $P_{t-b}$ belongs to the intervention component of the model (10), while the remaining part gives the ARIMA noise model (5). If the intervention component does not contain $P_{t-b}$ (or multiple numbered $P_{j, t-b}$ ), then there was no significant effect on HR for that event at a significance level of $\alpha=0.1$ and so no intervention component was included in the final model.

\subsection{General patterns of the noise ARIMA models}

The primary focus of this manuscript is on the intervention component rather than the noise component of the model because we are interested in modeling the effect of programmed audio cuing events and non-programmed physiological/environmental events on the pattern of HR changes, specifically the magnitude and duration of HR spikes. However, to briefly summarize the results of the ARIMA models for the noise (residual) series, we note that the majority of noise models were a simple autoregressive of order one, denoted ARIMA $(1,0,0)$, which has general form (ignoring the intervention component)

$$
y_{t}=\phi_{1} y_{t-1}+a_{t}
$$

(Box et al. 1994). For cow 4127, this noise model occurred in 5 out of $7 \mathrm{~A}$ events, for time intervals A1, A2, A4, A6 and A7 (Table 1A) and for both $E$ events (E1 and E2, Table 1B). For cow 4130, the noise model occurred for one $A$ event (A1, Table 2A) and for 2 of the $3 E$ events (E1 and E3, Table 2B). Finally for cow 4132, the ARIMA(1,0,0) noise model occurred for the only $A$ event (A1, Table 3A) and for all three of the $E$ events (E1, E2, and E3, Table 3B).

Noise models for the other five time intervals were more complicated and included nonseasonal and seasonal moving average and autoregressive terms, but it is easy to over-interpret what these noise models might mean. Note that the philosophy of the Box-Jenkins approach is to find a model or models that satisfy the diagnostics and not put too much emphasis on the actual form of the model (Box et al. 1994).

\subsection{General patterns of intervention models for cuing events}

The objective of this paper is to use time-series intervention analysis (Box and Tiao 1975; Box et al. 1994) to quantitatively model cow HR changes as functions of either programmed audio cues or non-programmed environmental/physiological events, with particular emphasis on estimating the magnitude and the duration of HR change and thereby provide insight into how DVFTM affects cow HR as a surrogate for stress. Among the total of $26 \mathrm{HR}$ spikes due to A events, there were three basic types of HR intervention models (note that for any time interval in which there 
was more than one intervention event, each event could have a different intervention component.). These three basic models are discussed in the following.

\subsubsection{Intervention models for audio cuing events having no significant intervention terms.} There were two $A$ events (cow 4127, A2, Table $1 \mathrm{~A}$ and cow 4130, A1, Table 2A) when a programmed cue should have caused a spike in HR based on the distance $(<100 \mathrm{~m})$ the cow was from the VCL ${ }^{\mathrm{TM}}$ but no significant HR spike was observed (data not shown). This resulted in a model that contained only the noise model, both of which were ARIMA $(1,0,0)$. For several time intervals containing more than one $A$ event, fitted models did not have significant parameters for every event in that time period. For example, for cow 4127 in time period A3 (Table 1A), there were eight separate audio events when the cow was $<100 \mathrm{~m}$ from the VCL ${ }^{\mathrm{TM}}$, but only two of those (P1 and P8) had significant parameters in the final model.

The fact that cuing did not produce a significant HR change may have been due to any of a number of factors including: failure of the piezo (speaker) to operate correctly in the DVF ${ }^{\mathrm{TM}}$ system, wind that may have reduced the effectiveness of the audio cue, the cow simply not responding to the cue, or the effect of the cue being masked by the inherent variability of the cow's HR at that particular time.

3.2.2. Intervention models for audio cuing events with one or more significant numerator parameters and no damping parameter. The majority of fitted intervention effects resulting from $A$ events had one or more numerator parameters ( $\omega$ parameter) but no damping (denominator or $\delta$ parameters) per event, and most of these had only one numerator parameter. For cow 4127 (Table 1A), models with a single numerator parameter occurred for: interval A3, event P8; interval A4, event P1; interval A6, event P3, and interval A7, event P2. For cow 4130 (Table 2A), models with a single numerator parameter occurred twice: interval A2, event P1; and interval A3, event P1. Cow 4132 (Table 3A) had one model with one numerator parameter (interval A1, event P1). Two events had more than numerator parameter. Cow 4127 (Table 1A) had four numerators parameters for interval A5, event P1, while cow 4132 had two numerator parameters for interval A1, event P1.

It is straight forward to determine the magnitude and duration of a HR increase where there is no damping parameter. For example, Fig. 2 shows the timeplot of audio cuing time interval A6 for cow 4127 (Table 1A). The vertical lines represent the occurrence of audio cuing events P1, P2 and P3 at 1223 hours, 1224 hours and 1343 hours, respectively. The first two events were not found to be statistically significant, and consequently there are no intervention components for these events in the final model. For the third event it can be seen from the timeplot (Fig. 2) that HR increases in the following minute, and then returns (statistically) back to normal in the next minute. From Table 1A, this third audio cuing event (P3) is shown to be modeled by an intervention component $\omega_{3,0} P_{3, t-1}$ with estimate $\hat{\omega}_{3,0}=10.70 \pm 3.37 \mathrm{bpm}$. This implies that following audio cuing at time $T=1343$ hours, the magnitude of the HR increase was $\hat{\omega}_{3,0}=10.70 \pm 3.37 \mathrm{bpm}$, which represents the increase compared to what HR would have been predicted without the intervention component in the model. This increase was observed in the 
next minute ( $T+1=1344$ hours), because $y_{T+1}$ was effected by the event in the previous minute $\left(P_{3, T}\right)$. This one-minute delay $\left(P_{3, t-1}\right)$ was expected because HR was only measured every minute and so the effect of the cuing should be observed in the HR of the next minute. This should always be true if HR measurement and cuing happened exactly at the same time. Unfortunately, the HR and the location were not measured concurrently in these data and this time-discrepancy may have caused problems in modeling. In reality, the cuing could have taken place, for example, half a minute earlier in the same minute compared to the HR measurement, and in this case we would have detected an "instantaneous" increase in the HR within the same minute. (One such "instantaneous" case was observed and is discussed after this example.)

Without a damping term in the model we are also able to make a clear statement about the duration of a HR increase, that is, how many minutes the effect of the cue lasted. This is done by inspecting the number of significant numerator terms in the intervention component. In the example of cuing event A6 for cow 4127, the duration was only one minute, because we only had one significant numerator term $\left(\hat{\omega}_{3,0}\right)$ in the model, which was at lag $1\left(P_{3, t-1}\right)$. This implies that the second measurement after the event at time $T+2=1345$ hours (Fig. 2) is not significantly different from what we would have expected according to the noise model alone.

The following example is a case (cow 4132, Table 3A, event A1) when there were two significant spikes (numerator terms) in the intervention component for the first audio cuing event (P1). The model component for event P1 contains two parameters, the first of which $\left(\omega_{1,0} P_{1, t}\right)$ shows an "instantaneous" (i.e., no delay) increase in HR (Table 3A). Fig. 3 shows the timeplot of this example, which is the only audio cuing interval for cow 4132. As before, the vertical lines show when the audio cues were administered, the first at 0047 hours and the second at 0058 hours. We can see that the effect of the first event on HR appeared to be instantaneous (i.e., we observed it within the same minute that cuing began), due to the two time-stamps, as previously discussed. The raw data were checked and it was verified that the cuing for the first event happened 31 s earlier than the HR measurement, which means that the effect of cuing may have been observed already in that measurement. The final fitted model and the parameter estimates can be found in Table 3A. Recall from the characteristics of the pulse function that for this intervention model (cow 4132, interval A1, event P1) $P_{1, t}=1$ only if $t=0047$ hours, and otherwise $P_{1, t}=0$. (In the same manner, $P_{2, t}=1$ only if $t=0058$ hours, and otherwise $P_{2, t}=0$.) According to this fitted model, the first event (P1) immediately increases the HR by $\hat{\omega}_{1,0}=26.25 \pm 3.37 \mathrm{bpm}$ at 0047 hours and also causes an increase of $-\hat{\omega}_{1,1}=10.41 \pm 3.33 \mathrm{bpm}$ at 0048 hours, as compared to the predicted value of that minute without taking the intervention into account. (Note that a minus sign occurs with $\hat{\omega}_{1,1}$, because intervention and time-series models are specified this way, with minus signs after the first term in a polynomial). Thus the first cuing event caused two consecutive spikes in HR, which then returned to normal, so the duration of the effect was two minutes. Similarly, the second event (P2) caused an estimated increase of $\hat{\omega}_{2,0}=6.33 \pm 3.15 \mathrm{bpm}$ observed with a delay of one minute $\left(P_{2, t-1}\right)$ with duration of 
one minute. It should be mentioned that the effect of $\hat{\omega}_{1,0}=26.25 \pm 3.37 \mathrm{bpm}$ was the biggest HR increase caused by audio cuing seen in the period March 19-24.

There was only one case when the duration of the effect was longer than one or two minutes, interval A5, $A$ event P1 for cow 4127. In Table 1A we see that for this event there were four significant consecutive numerator terms $\left(\hat{\omega}_{1,0}, \hat{\omega}_{1,1}, \hat{\omega}_{1,2}, \hat{\omega}_{1,3}\right)$ in the intervention component, and therefore the effect of audio cues lasted four minutes. This was unusual, and the only case in this data set. The overall magnitude of the effects were only around 5-6 bpm (Table 2A).

Significant spikes in HR due to audio cues ranged from 5 to 26 bpm among all cows and audio events. Statistical significance of these spikes was determined by the natural variability of HR in each time period. It can be seen that for intervals A4 and A7 for cow 4127 (Table 1A) and for interval A3 for cow 4130 (Table 2A), a nominal increase of approximately 5-6 bpm was found to be significant at $\alpha=0.1$, but those $p$-values were high (0.072, 0.087 and 0.095 , respectively). In other cases an increase of this magnitude was found to be significant with $p$-values much smaller than at $\alpha=0.1$ (like in the previous example, cow 4127, interval A5, event P1), because the background variability was lower (for example, compare Figs. 3 and 4). In some cases during the modeling process we did not find an increase of this magnitude to be statistically significant.

\subsubsection{Intervention models for cuing events with one significant spike and a single damping} parameter. An intervention model with a single numerator parameter and single damping parameter occurred for cow 4127 during time interval P1, P3, event 1 (Table 1A). For the first case, we kept a non-significant denominator term in the intervention model only because removing it adversely changed the fit of the model (as measured by the Chi-square goodness-offit test). For these models with one spike and a damping parameter, we define the magnitude of the effect as the estimated increase of the first spike $(\hat{\omega})$, from which the exponential decrease starts. When a damping term is in the intervention model, it is difficult to make accurate practical conclusions about the length of time of the effect of the event.

Fig. 4 shows the first hundred observations for cuing interval A3 for cow 4127 (Table 2A). The first vertical line represents the occurrence of the first event (P1) at $T=1634$ hours. It can be simply seen from the timeplot that HR increases in the following minute, then drops down. From Table $1 \mathrm{~A}$ this event is seen to be modeled by an intervention component $\frac{\omega_{1,0}}{1-\delta_{1,1} B} P_{1, t-1}$ with estimates $\hat{\omega}_{1,0}=17.70 \pm 4.07 \mathrm{bpm}$ and $\hat{\delta}_{1,1}=0.70 \pm .18$. This means that following cuing, the HR is estimated to have increased by $\hat{\omega}_{1,0}=17.70 \mathrm{bpm}$, followed by an exponential decrease at a rate of $\hat{\delta}_{1,1}=0.70$. The exponential decrease estimate of $\hat{\delta}_{1,1}=0.70$ theoretically means, that in the minutes $(T+2, T+3, \ldots)$ following the HR peak $\hat{\omega}_{1,0}=17.70 \mathrm{bpm}$ at $T+1=1635$ hours, the estimated HR will be $70 \%$ of the estimated increase of HR of each previous minute $(T+1, T+2$, ...). (Again, all these estimated increases are an increase compared to what would have been 
predicted without the intervention component if only fitting the noise model, e.g. we did not know about the intervention). The exponential decay pattern can be understood by performing polynomial long-division in our intervention model part and getting an infinite polynomial:

$$
\frac{\omega_{1,0}}{1-\delta_{1,1} B} P_{1, t-1}^{T}=\left(\omega_{1,0}+\omega_{1,0} \delta_{1,1} B+\omega_{1,0} \delta_{1,1}^{2} B^{2}+\omega_{1,0} \delta_{1,1}^{3} B^{3}+\ldots\right) P_{1, t-1}^{T},
$$

where $T=1634$ hours. In our example, equation (12) indicates that the audio cue increased the predicted $\mathrm{HR}$ by the following pattern: $\hat{\omega}_{1,0}=17.70 \mathrm{bpm}$ at 1635 hours, then $\hat{\omega}_{1,0} \hat{\delta}_{1,1}=17.70 \cdot 0.7=12.39 \mathrm{bpm}$ at 1636 hours, then $\hat{\omega}_{1,0} \hat{\delta}_{1,1}^{2}=17.70 \cdot 0.7^{2}=8.67 \mathrm{bpm}$ at 1637 hours, then $\hat{\omega}_{1,0} \hat{\delta}_{1,1}^{3}=17.70 \cdot 0.7^{3}=6.07 \mathrm{bpm}$ at 1638 hours, etc. (This example shows why $\delta=1$ represents a permanent change. In case of $\hat{\delta}_{1,1}=1$ our pattern would be $17.70,17.70 \cdot 1,17.70 \cdot 1^{2}$, $17.70 \cdot 1^{3}$, etc, which means that the HR increase of $\hat{\omega}_{1,0}=17.70 \mathrm{bpm}$ would not die out exponentially but would remain constant).

Care should be taken in drawing conclusions about these results because the HR pattern does not mean that those increases would all be significantly different from zero. It was of interest to explain how long the animal was affected by this cue, and this should not be done by simply inspecting the timeplot of HR. For instance a nominal estimated increase of $17.70 \cdot 0.7^{3}=6.07 \mathrm{bpm}$ (at time $T+4=1638$ hours) is not significantly different from zero in this period, because of the inherent variability in HR (Fig. 4). These data were refit with an alternative intervention model that included only single spikes (numerator terms) with no damping. The results suggest only the first and second spikes $\left(\omega_{0}\right.$ and $\left.\omega_{1}\right)$ were statistically significant. This would imply that the duration of the effect lasted two minutes. Fitting an exponential decay or denominator term $(\delta)$ in the model was done because the pattern of decrease from the timeplot suggested this to be true (Fig. 4), and this model satisfied the diagnostics and model-fit criteria somewhat better than the model with two HR spikes without damping.

When the cuing event continued into the following minute or the animal left but immediately returned to the $\mathrm{VB}^{\mathrm{TM}}$ within the next minute or two, the effects should be thought of as a combined effect, making it difficult to determine the contribution of each individual cue to the combined effect (e.g., event A5 for cow 4127).

\subsubsection{Intervention models for unidentified environmental/physiological non-programmed} cuing events. Two or three $E$ events that produced a noticeable increase in HR were chosen and modeled for each of the three cows to provide a comparison between programmed $A$ events and $E$ events. Environmental/physiological events were chosen where there was an occurrence of a visually obvious HR spike followed by a rapid $(\leq 3 \mathrm{~min})$ return of HR to its previous pattern, similar to what was seen with the programmed $\mathrm{DVF}^{\mathrm{TM}} A$ events. Note that these specifically chosen $E$ events are not meant to represent an exhaustive analysis of HR changes in general but are just to provide several basic comparisons. 
From Tables 1B (cow 4127), 2B (cow 4130), and 3B (cow 4132), it can be seen that many of the fitted intervention models were, in general, similar to those of the $A$ events. In particular, six models out of eight $E$ events were modeled with one or two significant spikes (numerator or $\omega$ parameters) with no damping term (cow 4127, time interval E1, events P1, P2 and P3; all three time intervals for cow 4130; and time intervals E1 and E2 for cow 4132). There was one model (interval E2 for cow 4127) with one significant spike and a single damping parameter (denominator or $\delta$ parameter), and there was a model (E3 for cow 4132) with one significant spike and a permanent mean shift in HR modeled by a single damping parameter close to one.

Fig. 5 is an example of a selected $E$ event (interval E2 for cow 4130) in which there was just one single large HR spike. The effect of the event was estimated to be an increase of $\hat{\omega}_{1,0}=44.66 \pm 4.05 \mathrm{bpm}$ (Table 2B). It can be seen that before and after the fifty-fifth minute lag the variance of the series differed, which is contrary to the assumptions of the general intervention model. Also the mean is slightly increasing over time. This has been previously document to occur for cows (Yamamoto et al. 1979) when a cow has been lying down and then gets up. However, this example does demonstrate that an unknown $E$ event can apparently cause a larger increase in HR than programmed $A$ cues. In contrast, the largest HR increase caused by the programmed audio cuing was $\hat{\omega}_{1,0}=26.25 \pm 3.37 \mathrm{bpm}$ (cow 4132, interval A1, Fig. 3). It should also be mentioned that environmental/physiological increases in HR of at least $20 \mathrm{bpm}$ was observed on each cow's timeplot over thirty times during the five-day period, suggesting the HR surge in Fig. 5 was not a rare event.

\section{CONCLUSIONS}

Cow HR has been described using regression (Yamamoto et al. 1979; Brosh et al. 1998), which is typically not appropriate for analyzing $\mathrm{HR}$ (or other physiological responses) measured consecutively over long time spans, as it fails to take serial correlation (i.e., non-independence) of readings into account. The DVFTM technology (Anderson 2007) combined with HR monitors on free-ranging cows over multiple days generates serially-correlated HR data and also cuing events that can change HR patterns. This paper has demonstrated the usefulness of time-series intervention analysis to quantitatively model both the magnitude and duration of HR changes over time as functions of either programmed audio cues arising from the DVFTM technology or non-programmed environmental/physiological events.

Because the HR data used in this paper came from only three cows being controlled with DVFTM over five consecutive days, the implications of this paper should focus mainly on the usefulness of time series intervention analysis in analyzing HR rather than on how much stress DVFTM control imparts to cows as measured by HR. However, even with the limited number of cows and length of time this study was conducted, these results do give insight into HR changes. First, there was much inter- and intra-cow variability of HR changes and the programmed audio cues did not consistently affect the HR of all cows in the same manner. Second, none of the HR spikes recorded when the cows received programmed audio cues were outside the range for 
"normal” cow HR reported in the literature. Third, although firm conclusions about the effect of environmental/physiological events on HR cannot be drawn because of how these events were selected for analysis, preliminary conclusions indicate that such events can result in HR spikes similar to or larger than those due to programmed audio cues.

\section{DISCLAIMER}

Mention of a trade name, proprietary product or vendor does not constitute a warranty of the product by the USDA, New Mexico State University or Kansas State University or imply its approval to the exclusion of other products or vendors that may also be suitable.

\section{ACKNOWLEDGEMENTS}

This research was approved by the New Mexico State University Institutional Animal Care and Use Committee (IACUC), Number 2003-003. Appreciation is expressed to colleagues and staff of the US Department of Agriculture - Agricultural Research Service, Jornada Experimental Range (USDA-ARS-JER) for helping to make this research possible. Special thanks go to $\mathrm{Mr}$ Roy Libeau, biological animal sciences technician JER for the animal husbandry and equipment maintenance and to NSF grant 0513755 for making the analyses of these data possible as partial fulfillment for Norbert Remenyi’s Experimental Statistics masters research project.

\section{REFERENCES}

Anderson, D. M. 2007. Virtual fencing - past, present and future. The Rangeland Journal, 29(1), $1-14$.

Anderson, D. M., and Hale, C. S. 2001. Animal control system using global positioning and instrumental animal conditioning. U. S. Patent 6,232,880. May 15. 18p. Int. Cl7 GO8B 23/00.

Anderson, D. M., Hale, C. S., Libeau, R.,and Nolen, B. 2003. Managing stocking density in real time. In: Proceedings of the VIIth International Rangeland Congress July 26 - Aug. 3, Durban, South Africa (Ed. by H. Allsopp, A. R. Palmer, S. J. Milton, K. P. Kirkman, G. H. I. Kerley, C. R. Hurt \& C. J. Brown), pp. 840-843.

Anderson, D. M., Smith, J. N., andHulet, C. V. 1985. Livestock behavior - The neglected link in understanding the plant/animal interface. In: Proceedings of a Conference on Multispecies Grazing, Winrock International Institute for Agricultural Development, Morrilton, AK. (Ed. by F. Baker, D. Childs), pp. 116-148.

Anonymous. 1986. Vital signs in animals. Doane's Agricultural Report, 49(42), 5-6.

Arnold, N.A., Ng, K.T., Jongman, E.C., and Hemsworth, P.H. 2007. The behavioural and physiological responses of dairy heifers to tape-recorded milking facility noise with and without a pre-treatment adaptation phase. Applied Animal Behaviour Science, 106, 13-25.

Baldock, N.M., and Sibly, R.M. 1990. Effects of handling and transportation on the heart rate and behaviour of sheep. Applied Animal Behaviour Science, 28, 15-39.

Besch, E.L., Varosi, S.M., and Brigmon, R.L. 1992. Technical note: A noninvasive procedure for measuring goat heart rates. Journal of Animal Science, 70, 3371-3375. 
Box, G. E. P, Jenkins, G. M., and Reinsel, G. C. 1994. Time Series Analysis: Forecasting and Control. $3^{\text {rd }}$ edn. Englewood Cliffs: Prentice-Hall.

Box, G. E. P., and Tiao, G. C. 1975. Intervention analysis with applications to economic and environmental problems. Journal of the American Statistical Association, 70(349), 70-79.

Brocklebank, J., and Dickey, D. 2003. SAS® System for Forecasting time Series. ${ }^{\text {nd }}$ edn. Cary: SAS Institute Inc.

Brosh, A. 2007. Heart rate measurements as an index of energy expenditure and energy balance in ruminants: A review. Journal of Animal Science, 85, 1213-1227.

Brosh, A., Aharoni, Y., Degen, A. A., Wright, D., and Young, B. 1998. Estimation of energy expenditure from heart rate measurements in cattle maintained under different conditions. Journal of Animal Science, 76, 3054-3064.

Brosh, A., Henkin, Z., Ungar, E.D., Dolev, A., Orlov, A., Yehuda, Y., and Aharoni, Y. 2006. Energy cost of cows' grazing activity: Use of the heart rate method and the Global Positioning System for direct field estimation. Journal of Animal Science, 84, 1951-1967.

Buckhouse, J. C., and Winward, A. H. 1976. Barbed wire tells it all. Rangeman's Journal, 3(3), 77-78.

Cook, C. J., and Jacobson, L. H. 1996. Heart rate as a measure of adaptation to stress in cattle. Australian Veterinary Journal, 74(6), 471-472.

Croney, C. C., and Millman, S. T. 2007. The ethical and behavioral bases for farm animal welfare legislation. Journal of Animal Science, 85, 556-565.

Deag, J. M. 1996. Behavioural ecology and the welfare of extensively farmed animals. Applied Animal Behavior Science, 49, 9-22.

Gorewit, R.C., and Scott, N.R. 1986. Cardiovascular response of cows given electrical current during milking. Journal of Dairy Science, 69, 1122-1127.

Gygax, L., Neuffer, I., Kaufmann, C., Hauser, R., and Wechsler, B. 2008. Restlessness behaviour, heart rate and heart-rate variability of dairy cows milked in two types of automatic milking systems and auto-tandem milking parlours. Applied Animal Behaviour Science, 109, 167-179.

Hagen, K., Langbein, J., Schmied, C., Lexer, D., and Waiblinger, S. 2005. Heart rate variability in dairy cows - influences of breed and milking system. Physiology and Behavior, 85, 195-204.

Hopster, H., and Blokhuis, H. J. 1994. Validation of a heart rate monitor for measuring a stress response in dairy cows. Canadian Journal of Animal Science, 74, 465-474.

Hulet, C. V., Anderson, D. M., Nakamatsu, V. B., Murray, L. W., and Pieper, R. D. 1982. Diet selection of cattle and bonded small ruminants grazing arid rangeland. Sheep Research Journal, 8, 11-18.

Janžekovič, M., Muršec, B., and Janžekovič, I. 2006. Techniques of measuring heart rate in cattle. Tehnicki Vjesnik, 13 (1-2), 31-37.

Lay, D.C. Jr., Friend, T.H., Randel, R.D., Bowers, C.L., Grissom, K.K., and Jenkins, O.C. 1992. Behavioral and physiological effects of freeze or hot-iron branding on crossbred cattle. Journal of Animal Science, 70, 330-336.

Lefcourt, A. M., Kahl, S., and Akers, R. M. 1986. Correlation of indices of stress with intensity of electrical shock for cows. Journal of Dairy Science, 69, 833-342. 
McCallum, H. D., and McCallum, F. T. 1965. The Wire that Fenced the West. Norman: University of Oklahoma Press.

McGuirk, S.M., Bednarski, R.M., and Clayton, M.K. 1990. Bradycardia in cattle deprived of food. Journal of the American Veterinary Medical Association, 196 (6), 894-896.

Monger, H. C. 2006. Soil development in the Jornada Basin. In: Structure and function of a Chihuahuan Desert Ecosystem (Ed. by K. M. Havstad, L. F. Huenneke \& W. H. Schlesinger), pp. 81-106. New York: Oxford University Press.

Montgomery, D. C., Johnson L. A., and Gardiner J. S. 1990. Forecasting and time series analysis. $2^{\text {nd }}$ edn. New York: McGraw-Hill, Inc.

Palestrini, C., Ferrante, V., Mattiello, S., Canali, E., and Carenzi, C. 1998. Relationship between behaviour and heart rate as an indicator of stress in domestic sheep under different housing systems. Small Ruminant Research, 27, 177-181.

Pankratz, A. 1991. Forecasting with dynamic regression models. New York: John Wiley \& Sons, Inc.

Paulsen, H. A. Jr., and Ares, F. N. 1962. Grazing values and management of black grama and tobosa grasslands and associated shrub ranges of the Southwest. Forest Service Technical Bulletin 1270. Washington: U.S. Government Printing Office.

Porges, S. W. 1985. Spontaneous oscillations in heart rate: Potential index of stress. In: Animal stress (Ed. by G. P. Moberg), pp. 97-111. Baltimore: The Williams and Wilkins Company.

Rango, A., Anderson, D. M., Hale, C. S., and Havstad, K. M. 2003. A developing method for Directional Virtual Fencing $\left(\mathrm{DVF}^{\mathrm{TM}}\right)$ and real time range management using remote sensing, GIS and GPS. In: Proceedings of the $30^{\text {th }}$ International Symposium on Remote Sensing of Environment. November 10-14, 2003 Honolulu, Hawaii, Paper No. TS-11.4.

Richards, J.I., and Lawrence, P.R. 1984. The estimation of energy expenditure from heart rate measurements in working oxen and buffalo. Journal of Agricultural Science, 102, 711717.

Robinett, D. Miler, D., and Bedunah, D. 2008. Central Afghanistan rangelands -- A history of tribal rule, grazing, war and rebuilding. Rangelands, 30 (4), 2-12.

Rometsch, M., and Becker, K. 1993. Determination of the reaction of heart rate of oxen to draught work with a portable data-acquisition system. Journal of Agricultural Engineering Research, 54, 29-36.

SAS Institute. 1999. SAS/STAT®, User's Guide, Version 8. Cary: SAS Institute Inc.

Smith, B. 1988. Moving'em - A guide to low stress animal handling. Kamela: The Graziers Hui.

Von Borell, E. Langbein, J Després, Hansen S. Leterrier, C. Marchant-Forde, J. MarchantForde, R. Minero, M. Mohr, E. Prunier, A. Valance, D., and Veissier, I. 2007. Heart rate variability as a measure of antonomic regulation of cardiac activity for assessing stress and welfare in farm animals - A review. Physiology and Behavior, 92, 293-316.

Yamamoto, S., McLean, J. A., and Downie, A. J. 1979. Estimation of heat production from heart-rate measurements in cattle. British Journal of Nutrition, 42, 507-513.

Youatt, W. 1836. Cattle their Breeds, Management and Diseases. Philadelphia: Grigg and Elliot.

Vandaele, W. 1983. Applied Time Series and Box-Jenkins Models. Orlando: Academic Press. 
Wainright, J. 2006. Climate and climatological variations in the Jornada Basin. In: Structure and function of a Chihuahuan Desert Ecosystem (Ed. by K. M. Havstad, L. F. Huenneke \& W. H. Schlesinger), pp. 44-80. New York: Oxford University Press.

Zakynthinaki, M.S., and Stirling, J.R. 2007. Stochastic optimization for modeling physiological time series: application to the heart rate response to exercise. Computer Physics Communications, 176, 98-108. 


\section{Table 1A}

Final intervention models with accompanying statistics for describing the effect programmed audio cues had on the heart rate (HR) of free-ranging cow 4127 between 19 and 22 March 2003 once the animal had penetrated a virtual boundary (VB ${ }^{\mathrm{TM}}$ ) as part of a directional virtual fencing (DVFTM) system for controlling an animal's location on a landscape. See Anderson (2007) for details on DVFTM animal control

\begin{tabular}{|c|c|c|c|c|c|}
\hline Day & $\begin{array}{l}\text { Time interval of } \\
\text { audio (A) } \\
\text { cuing events } \\
\text { (Military) }\end{array}$ & $\begin{array}{c}\text { Time of } \\
\text { each } \\
\text { event } \\
\text { (Number) }\end{array}$ & $\begin{array}{c}\text { Intervention Model } \\
y_{t}=\frac{\omega(B)}{\delta(B)} P_{t-b}+N_{t} \\
\text { (General model) }\end{array}$ & $\begin{array}{l}\text { Mean Square } \\
\text { Error } \\
\text { (Error degrees } \\
\text { of freedom) }\end{array}$ & $\begin{array}{l}\text { Goodness-of-fit p- } \\
\text { value } \\
\text { (Lag calculated at) }\end{array}$ \\
\hline 19 & $\mathrm{~A} 1=1725-1845$ & $1825(\mathrm{P} 1)^{1}$ & $\begin{aligned} y_{t}=\frac{\omega_{0}}{1-\delta_{1} B} P_{1, t-2}+\phi_{1} y_{t-1} & a_{t} \\
& \hat{\omega}_{0}: 12.94 \pm 2.83(p=<.0001) \\
& \hat{\delta}_{1}: 0.09 \pm 0.23(p=0.694) \\
& \hat{\phi}_{1}: 0.71 \pm 0.09(p=<.0001)\end{aligned}$ & $\begin{array}{l}8.61 \\
(74)\end{array}$ & $\begin{array}{l}0.23 \\
(18)\end{array}$ \\
\hline 20 & $\mathrm{~A} 2=0649-0810$ & $\begin{array}{l}0749(\mathrm{P} 1) \\
0750(\mathrm{P} 2)\end{array}$ & $\hat{\phi}_{1}: 0.63 \pm 0.09(p=<.0001)$ & $\begin{array}{l}7.09 \\
(80)\end{array}$ & $\begin{array}{l}0.67 \\
(18)\end{array}$ \\
\hline 21 & A3 = 1534-1853 & $\begin{array}{c}1634(\mathrm{P} 1)^{1} \\
1653(\mathrm{P} 2) \\
1730(\mathrm{P} 3) \\
1732(\mathrm{P} 4) \\
1750(\mathrm{P} 5) \\
1818(\mathrm{P} 6) \\
1832(\mathrm{P} 7) \\
1833(\mathrm{P} 8)^{1}\end{array}$ & $\begin{aligned} y_{t}=\frac{\omega_{1,0}}{1-\delta_{1,1} B} P_{1, t-1}+\omega_{8,0} P_{8, t-1}+\phi_{1} y_{t-1}+a_{t}-\theta_{2} a_{t-2} \\
\hat{\omega}_{1,0}: 17.70 \pm 4.07(p=<.0001) \\
\hat{\delta}_{1,1}: 0.70 \pm 0.18(p=<.0001) \\
\hat{\omega}_{8,0}: 8.79 \pm 3.15(p=0.006) \\
\hat{\phi}_{1}: 0.82 \pm 0.05(p=<.0001) \\
\hat{\theta}_{2}: 0.22 \pm 0.08(p=0.009)\end{aligned}$ & $\begin{array}{l}17.14 \\
(192)\end{array}$ & $\begin{array}{l}0.80 \\
(48)\end{array}$ \\
\hline 21 and 22 & $\mathrm{~A} 4=2309-0030$ & $\begin{array}{c}0009(\mathrm{P} 1)^{1} \\
0011(\mathrm{P} 2)\end{array}$ & $\begin{array}{ll}y_{t}=\omega_{0} P_{1, t-2}+\phi_{1} y_{t-1}+a_{t} & \\
& \hat{\omega}_{0}: 5.02 \pm 2.75(p=0.072) \\
& \hat{\phi}_{1}: 0.79 \pm 0.07(p=<.0001)\end{array}$ & $\begin{array}{c}12.37 \\
(77)\end{array}$ & $\begin{array}{l}0.27 \\
(18)\end{array}$ \\
\hline
\end{tabular}


Table 1A (Continued)

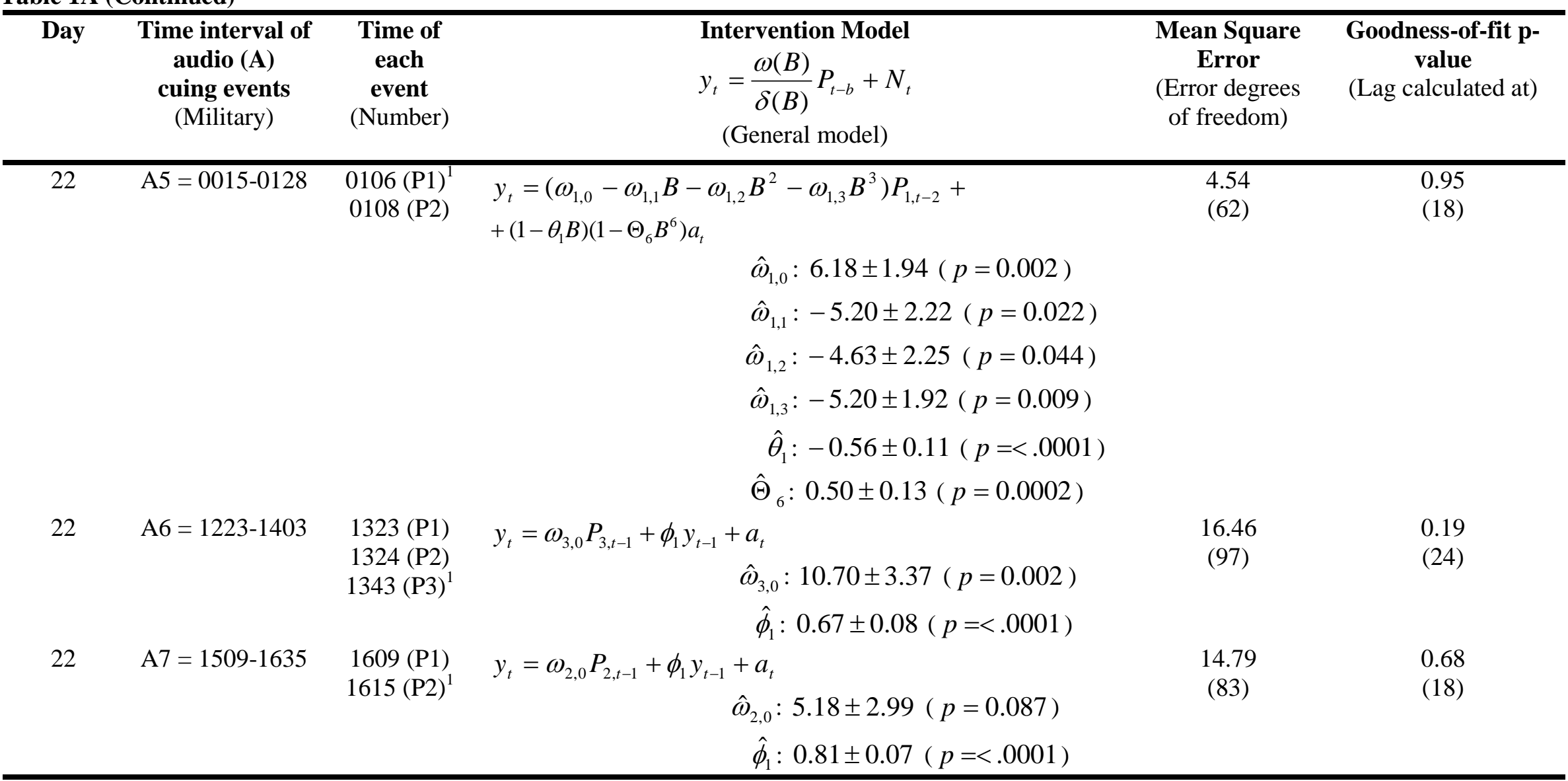

\footnotetext{
${ }^{1}$ Indicates that a particular cuing event caused a statistically significant change in HR at $\alpha=.10$.
} 


\section{Table 1B}

Final intervention models with accompanying statistics for describing the effect non-programmed environmental and or physiological cues had on the heart rate (HR) of free-ranging cow 4127 between 21 and 24 March 2003 as the animal was within a virtual paddock (VPTM) as part of a directional virtual fencing (DVFTM) system for controlling an animal's location on a landscape. See Anderson (2007) for details on DVF ${ }^{\mathrm{TM}}$ animal control

\begin{tabular}{|c|c|c|c|c|c|}
\hline Day & $\begin{array}{l}\text { Time interval of } \\
\text { environmental/ } \\
\text { physiological (E) } \\
\text { events } \\
\text { (Military) }\end{array}$ & $\begin{array}{c}\text { Time of } \\
\text { each } \\
\text { event } \\
\text { (Number) }\end{array}$ & $\begin{array}{c}\text { Intervention Model } \\
y_{t}=\frac{\omega(B)}{\delta(B)} P_{t-b}+N_{t} \\
\text { (General model) }\end{array}$ & $\begin{array}{c}\text { Mean Square } \\
\text { Error } \\
\text { (Error degrees } \\
\text { of freedom) }\end{array}$ & $\begin{array}{l}\text { Goodness-of-fit p- } \\
\text { value } \\
\text { (Lag calculated at) }\end{array}$ \\
\hline 21 & $\mathrm{E} 1=1950-2135$ & $\begin{array}{l}2050(\mathrm{P} 1)^{1} \\
2059(\mathrm{P} 2)^{1} \\
2115(\mathrm{P} 3)^{1}\end{array}$ & $\begin{aligned} y_{t}=\omega_{1,0} P_{1, t-1}+\omega_{2,0} P_{2, t-1}+\omega_{3,0} P_{3, t-1}-\omega_{3,1} P_{3, t-2}+\phi_{1} y_{t-1}+a_{t} \\
\hat{\omega}_{1,0}: 14.52 \pm 2.02(p=<.0001) \\
\hat{\omega}_{2,0}: 9.30 \pm 1.99(p=<.0001) \\
\hat{\omega}_{3,0}: 15.58 \pm 2.05(p=<.0001) \\
\hat{\omega}_{3,1}:-11.76 \pm 2.04(p=<.0001) \\
\hat{\phi}_{1}: 0.24 \pm 0.10(p=0.021)\end{aligned}$ & $\begin{array}{l}4.16 \\
(98)\end{array}$ & $\begin{array}{l}0.09 \\
(24)\end{array}$ \\
\hline 24 & E2 = 1223-1343 & $1323(\mathrm{P} 1)^{1}$ & $\begin{aligned} & y_{t}=\frac{\omega_{0}}{1-\delta_{1} B} P_{1, t-1}+\phi_{1} y_{t-1}+a_{t} \\
& \hat{\omega}_{0}: 36.54 \pm 4.91(p=<.0001) \\
& \hat{\delta}_{1}: 0.38 \pm 0.13(p=0.004) \\
& \hat{\phi}_{1}: 0.40 \pm 0.11(p=0.0003)\end{aligned}$ & $\begin{array}{c}23.84 \\
(75)\end{array}$ & $\begin{array}{l}0.97 \\
(18)\end{array}$ \\
\hline
\end{tabular}

\footnotetext{
${ }^{1}$ Indicates that a particular cuing event caused a statistically significant change in HR at $\alpha=.10$.
} 


\section{Table 2A}

Final intervention models with accompanying statistics for describing the effect programmed audio cues had on the heart rate (HR) of free-ranging cow 4130 between 19 and 23 March 2003 once the animal had penetrated a virtual boundary (VB ${ }^{\mathrm{TM}}$ ) as part of a directional virtual fencing (DVFTM) system for controlling an animal's location on a landscape. See Anderson (2007) for details on DVFTM animal control

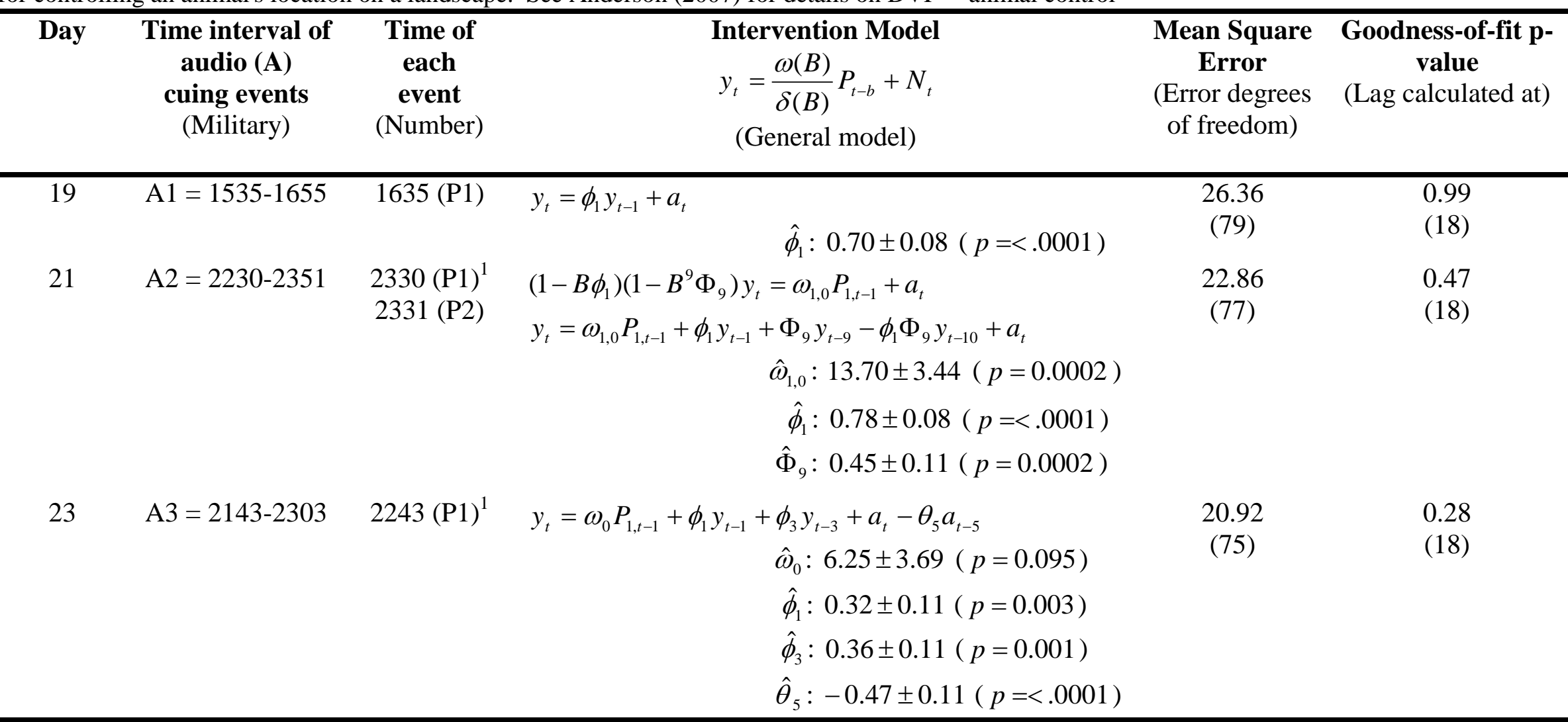

\footnotetext{
${ }^{1}$ Indicates that a particular cuing event caused a statistically significant change in HR at $\alpha=.10$.
} 


\section{Table 2B}

Final intervention models with accompanying statistics for describing the effect non-programmed environmental and or physiological cues had on the heart rate (HR) of free-ranging cow 4130 between 21 and 24 March 2003 as the animal was within a virtual paddock (VPTM) as part of a directional virtual fencing (DVFTM) system for controlling an animal's location on a landscape. See Anderson (2007) for details on DVFTM animal control

\begin{tabular}{|c|c|c|c|c|c|}
\hline Day & $\begin{array}{c}\text { Time interval of } \\
\text { environmental/ } \\
\text { physiological (E) } \\
\text { events } \\
\text { (Military) }\end{array}$ & $\begin{array}{c}\text { Time of } \\
\text { each } \\
\text { event } \\
\text { (Number) }\end{array}$ & $\begin{array}{c}\text { Intervention Model } \\
y_{t}=\frac{\omega(B)}{\delta(B)} P_{t-b}+N_{t} \\
\text { (General model) }\end{array}$ & $\begin{array}{l}\text { Mean Square } \\
\text { Error } \\
\text { (Error degrees } \\
\text { of freedom) }\end{array}$ & $\begin{array}{l}\text { Goodness-of-fit } \\
\text { p-value } \\
\text { (Lag calculated at) }\end{array}$ \\
\hline 21 & $\mathrm{E} 1=1814-1934$ & $1914(\mathrm{P} 1)^{1}$ & $\begin{aligned} & y_{t}=\omega_{0} P_{1, t-1}+\phi_{1} y_{t-1}+a_{t} \\
& \hat{\omega}_{0}: 26.06 \pm 3.59(p=<.0001) \\
& \hat{\phi}_{1}: 0.84 \pm 0.07(p=<.0001)\end{aligned}$ & $\begin{array}{c}21.88 \\
(77)\end{array}$ & $\begin{array}{l}0.07 \\
(18)\end{array}$ \\
\hline 23 & $\mathrm{E} 2=1510-1630$ & $1610(\mathrm{P} 1)^{1}$ & $\begin{aligned} &\left(1-\phi_{1} B\right)\left(1-\Phi_{3} B^{3}\right) y_{t}=\omega_{0} P_{t-1}+a_{t} \\
& y_{t}=\omega_{0} P_{1, t-1}+\phi_{1} y_{t-1}+\Phi_{3} y_{t-4}-\phi_{1} \Phi_{3} y_{t-4}+a_{t} \\
& \hat{\omega}_{0}: 44.66 \pm 4.05(p=<.0001) \\
& \hat{\phi}_{1}: 0.71 \pm 0.09(p=<.0001) \\
& \hat{\Phi}_{3}: 0.33 \pm 0.12(p=0.008)\end{aligned}$ & $\begin{array}{c}27.34 \\
(76)\end{array}$ & $\begin{array}{l}0.35 \\
(18)\end{array}$ \\
\hline
\end{tabular}

\footnotetext{
${ }^{1}$ Indicates that a particular cuing event caused a statistically significant change in HR at $\alpha=.10$.
} 


\section{Table 3A}

Final intervention models with accompanying statistics for describing the effect programmed audio cues had on the heart rate (HR) of free-ranging cow 4132 between 21 and 22 March 2003 once the animal had penetrated a virtual boundary (VB ${ }^{\mathrm{TM}}$ ) as part of a directional virtual fencing (DVFTM) system for controlling an animal's location on a landscape. See Anderson (2007) for details on DVFTM animal control

\begin{tabular}{|c|c|c|c|c|c|}
\hline Day & $\begin{array}{l}\text { Time interval of } \\
\text { audio (A) } \\
\text { cuing events } \\
\text { (Military) }\end{array}$ & $\begin{array}{c}\text { Time of } \\
\text { each } \\
\text { event } \\
\text { (Number) }\end{array}$ & $\begin{array}{l}\text { Intervention Model } \\
y_{t}=\frac{\omega(B)}{\delta(B)} P_{t-b}+N_{t} \\
\text { (General model) }\end{array}$ & $\begin{array}{l}\text { Mean Square } \\
\text { Error } \\
\text { (Error degrees } \\
\text { of freedom) }\end{array}$ & $\begin{array}{c}\text { Goodness-of-fit p- } \\
\text { value } \\
\text { (Lag calculated at) }\end{array}$ \\
\hline 21 and 22 & $\mathrm{~A} 1=2347-0118$ & $\begin{array}{l}0047(\mathrm{P} 1)^{1} \\
0058(\mathrm{P} 2)^{1}\end{array}$ & $\begin{aligned} y_{t}=\omega_{1,0} P_{1, t}-\omega_{1,1} P_{1, t-1}+\omega_{2,0} P_{2, t-1}+\phi_{1} y_{t-1}+a_{t} \\
\hat{\omega}_{1,0}: 26.25 \pm 3.37(p=<.0001) \\
\hat{\omega}_{1,1}:-10.41 \pm 3.33(p=0.002) \\
\hat{\omega}_{2,0}: 6.33 \pm 3.15(p=0.048) \\
\hat{\phi}_{1}: 0.33 \pm 0.10(p=0.002)\end{aligned}$ & $\begin{array}{c}10.96 \\
(86)\end{array}$ & $\begin{array}{l}0.52 \\
(24)\end{array}$ \\
\hline
\end{tabular}

\footnotetext{
${ }^{1}$ Indicates that a particular cuing event caused a statistically significant change in HR at $\alpha=.10$.
} 


\section{Table 3B}

Appropriate intervention models with accompanying statistics for describing the effect non-programmed environmental and or physiological cues had on the heart rate (HR) of free-ranging cow 4132 between 19 and 24 March 2003 as the animal was within a virtual paddock (VP'M) as part of a directional virtual fencing (DVF ${ }^{\mathrm{TM}}$ ) system for controlling an animal's location on a landscape. See Anderson (2007) for details on DVFTM animal control

\begin{tabular}{|c|c|c|c|c|c|}
\hline Day & $\begin{array}{l}\text { Time interval of } \\
\text { environmental/ } \\
\text { physiological (E) } \\
\text { cuing events } \\
\text { (Military) }\end{array}$ & $\begin{array}{c}\text { Time of } \\
\text { each } \\
\text { event } \\
\text { (Number) }\end{array}$ & $\begin{array}{l}\text { Intervention Model } \\
y_{t}=\frac{\omega(B)}{\delta(B)} P_{t-b}+N_{t} \\
\text { (General model) }\end{array}$ & $\begin{array}{c}\text { Mean Square } \\
\text { Error } \\
\text { (Error degrees } \\
\text { of freedom) }\end{array}$ & $\begin{array}{l}\text { Goodness-of-fit p- } \\
\text { value } \\
\text { (Lag calculated at) }\end{array}$ \\
\hline 19 & $E 1=1857-2017$ & $1957(\mathrm{P} 1)^{1}$ & $\begin{aligned} & y_{t}=\omega_{0} P_{1, t-1}-\omega_{1} P_{1, t-2}+ \phi_{1} y_{t-1}+a_{t} \\
& \hat{\omega}_{0}: 29.06 \pm 2.97(p=<.0001) \\
& \hat{\omega}_{1}:-6.27 \pm 2.94(p=0.036) \\
& \hat{\phi}_{1}: 0.42 \pm 0.11(p=0.0002)\end{aligned}$ & $\begin{array}{l}8.69 \\
(75)\end{array}$ & $\begin{array}{l}0.92 \\
(18)\end{array}$ \\
\hline 23 & $\mathrm{E} 2=1106-1226$ & $1206(\mathrm{P} 1)^{1}$ & $\begin{aligned} & y_{t}=\omega_{0} P_{1, t-1}-\omega_{1} P_{1, t-2}+ \phi_{1} y_{t-1}+a_{t} \\
& \hat{\omega}_{0}: 29.88 \pm 2.06(p=<.0001) \\
& \hat{\omega}_{1}:-24.93 \pm 2.06(p=<.0001) \\
& \hat{\phi}_{1}: 0.47 \pm 0.10(p=<.0001)\end{aligned}$ & $\begin{array}{l}4.34 \\
(75)\end{array}$ & $\begin{array}{l}0.67 \\
(18)\end{array}$ \\
\hline 24 & $\mathrm{E} 3=0053-0213$ & $0153(\mathrm{P} 1)^{1}$ & $\begin{aligned} & y_{t}=\frac{\omega_{0}-\omega_{1} B}{1-\delta_{1} B} P_{1, t-1}+ \phi_{1} y_{t-1}+a_{t} \\
& \hat{\omega}_{0}: 30.39 \pm 2.16(p=<.0001) \\
& \hat{\omega}_{1}: 15.51 \pm 2.45(p=<.0001) \\
& \hat{\delta}_{1}: 0.99 \pm 0.01(p=<.0001) \\
& \hat{\phi}_{1}: 0.62 \pm 0.09(p=<.0001)\end{aligned}$ & $\begin{array}{l}5.03 \\
(74)\end{array}$ & $\begin{array}{l}0.80 \\
(18)\end{array}$ \\
\hline
\end{tabular}

\footnotetext{
${ }^{1}$ Indicates that a particular cuing event caused a statistically significant change in HR at $\alpha=.10$.
} 
Key : (+) Indicates increasing intensity

$0=$ Virtual Boundary $\left(\mathrm{VB}^{\mathrm{TM}}\right), 200 \mathrm{~m}$ wide

$1=$ Virtual Paddock (VP ${ }^{\text {TM }}$ ) with animals

$2=(+)$ audio only

$3=(+)$ audio $\&(+)$ electrical stimulation

$4=(++)$ audio $\&(++)$ electrical stimulation

$5=(+++)$ audio \& $(+++)$ electrical stimulation

$6=\mathrm{VP}^{\mathrm{TM}}$ without animals

$7=$ Virtual Center Line $\left(\mathrm{VCL}^{\mathrm{TM}}\right)$

$8=$ Angle of approach to $\mathrm{VCL}^{\mathrm{TM}}$
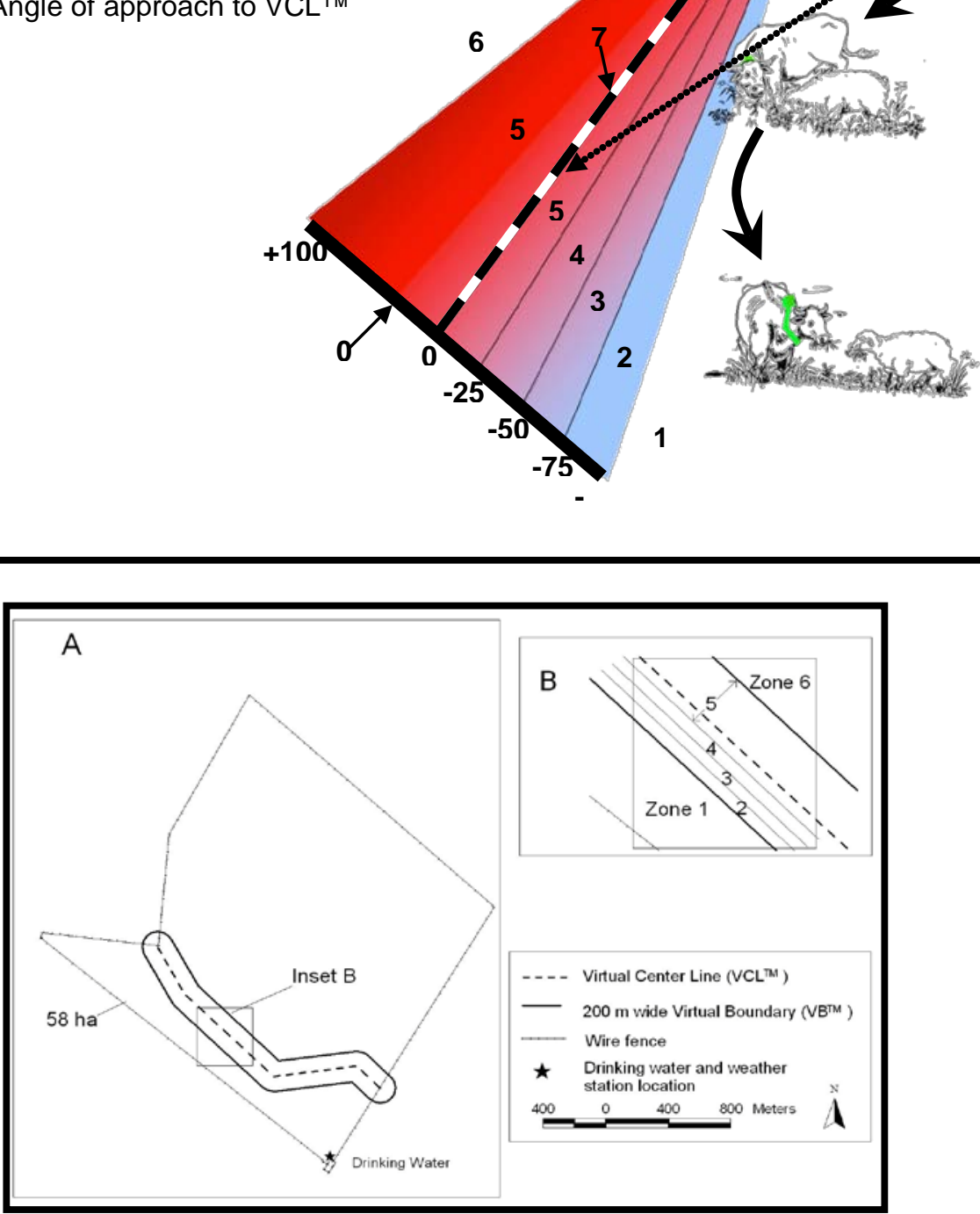

Fig. 1. Schematic of Directional Virtual Fencing $\left(D F^{\mathrm{TM}}\right.$; adapted from Anderson et al., 2003). Insert A shows the location of a virtual boundary (VB ${ }^{\mathrm{TM}}$ ) in Paddock 10B (466 ha), Jornada Experimental Range, during March 2003. The southern 58 ha of Paddock 10B that was stocked with three cows is shown as Zone 1 in inset $\mathrm{B}$. The $\mathrm{VB}^{\mathrm{TM}}$ was composed of Zones 2-4 each $25 \mathrm{~m}$ wide and Zone 5 that was $125 \mathrm{~m}$ in width. 


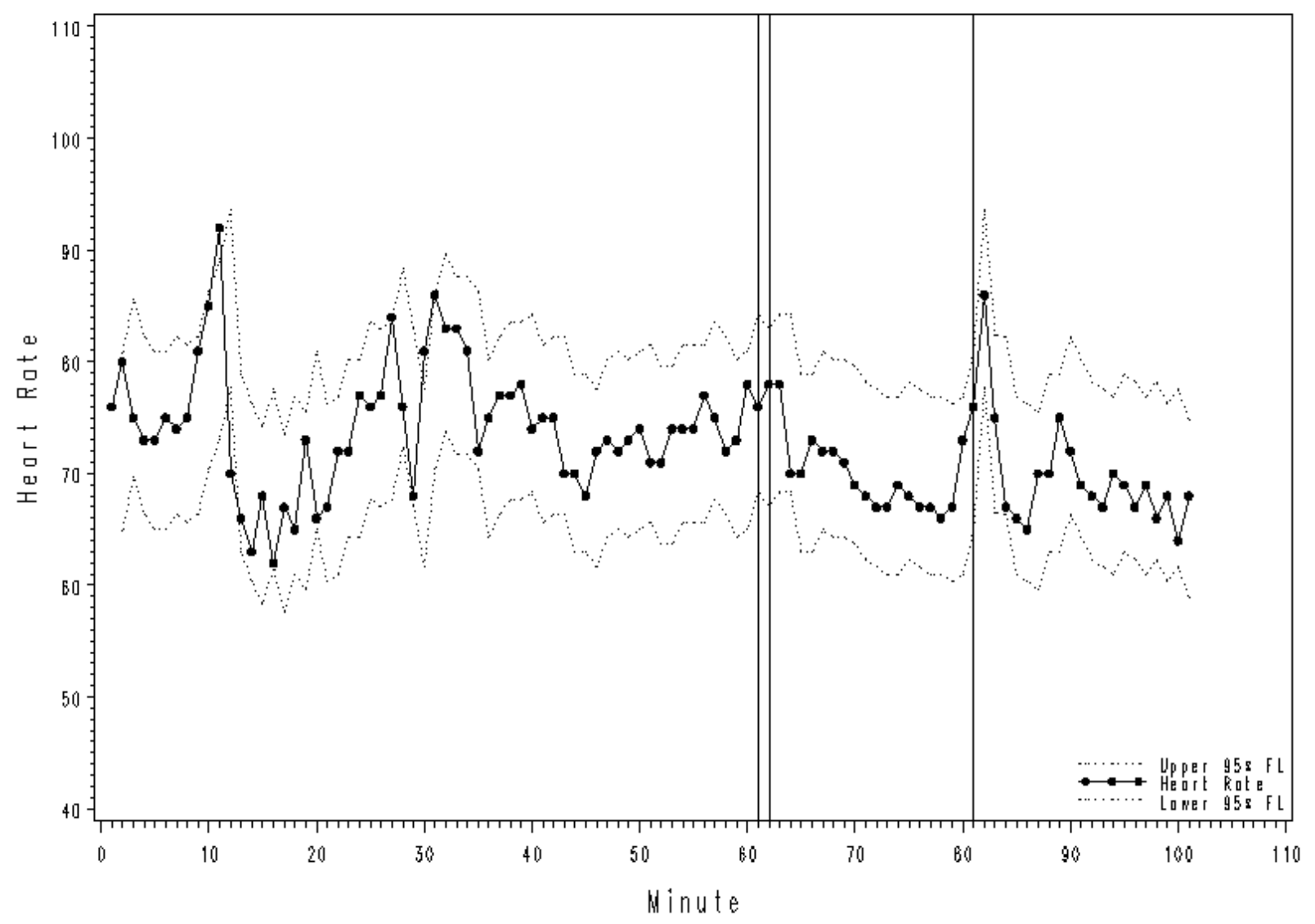

Fig. 2. Heart rate (HR) timeplot for a programmed cuing event period A6 for cow 4127 between $1223 \mathrm{hrs}$ and $1403 \mathrm{hrs}$ on 22 March, 2003. Vertical axis is HR in beats per minute (bpm), horizontal axis is time in minutes, beginning at 1223 hrs. The first vertical line at minute 61 (1223 hrs) represents the first cuing event (1). The second vertical line at minute 62 (1224 hrs) represents the second cuing event (2). The third vertical line at minute 81 (1343 hrs) represents the third cuing event (3). Dotted lines represent 95\% lower and upper forecast limits based on the fitted intervention model. 


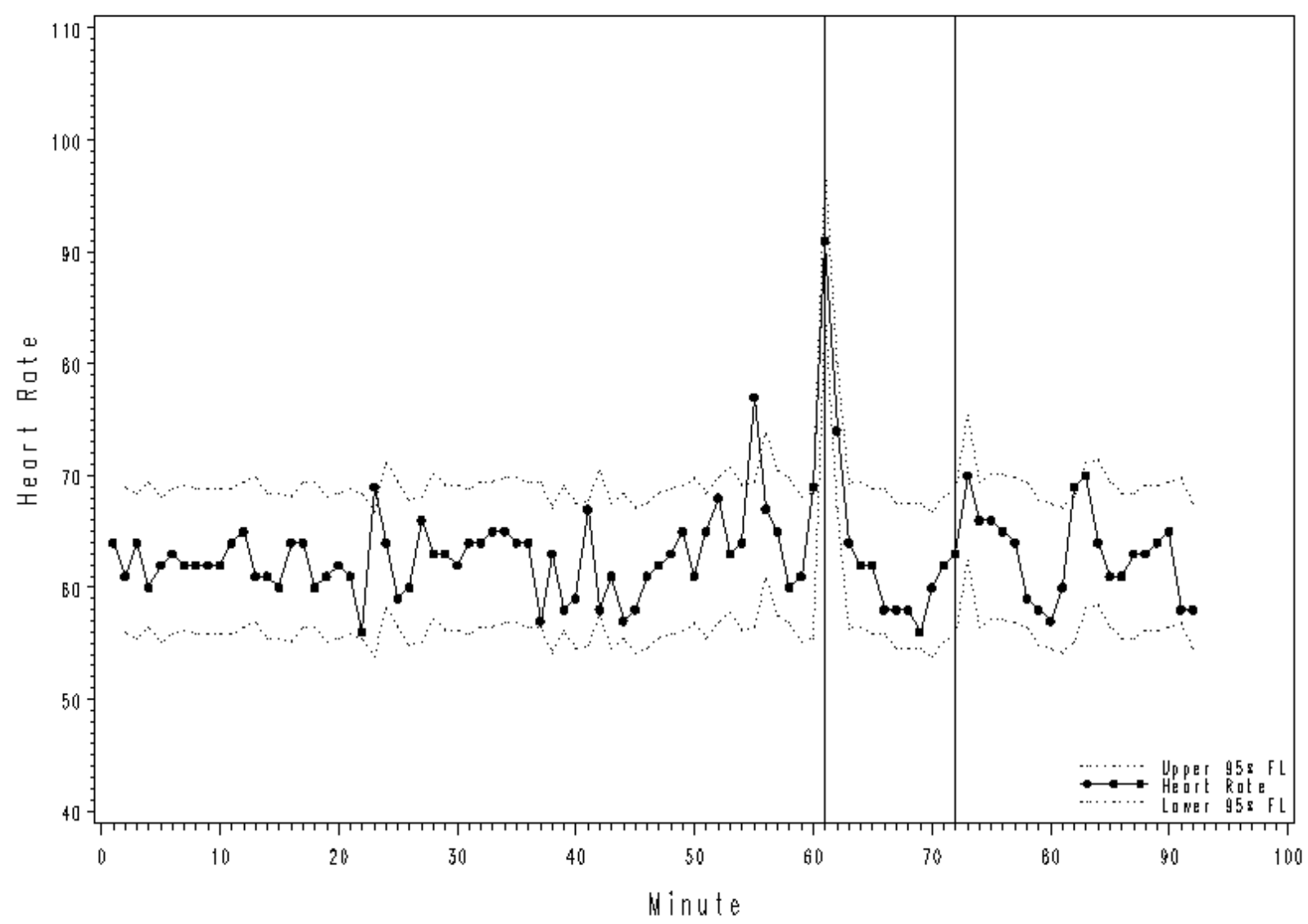

2 Fig. 3. Heart rate (HR) timeplot for a programmed cuing event period A1 for cow 4132 between 32347 hrs and 0118 hrs on 21-22 March, 2003. Vertical axis is HR in beats per minute (bpm), 4 horizontal axis is time in minutes, beginning at $2347 \mathrm{hrs}$. The first vertical line at minute 61 5 (0047 hrs) represents the first cuing event (1). The second vertical line at minute 72 (0058 hrs) 6 represents the second cuing event (2). Dotted lines represent 95\% lower and upper forecast limits 7 based on the fitted intervention model. 


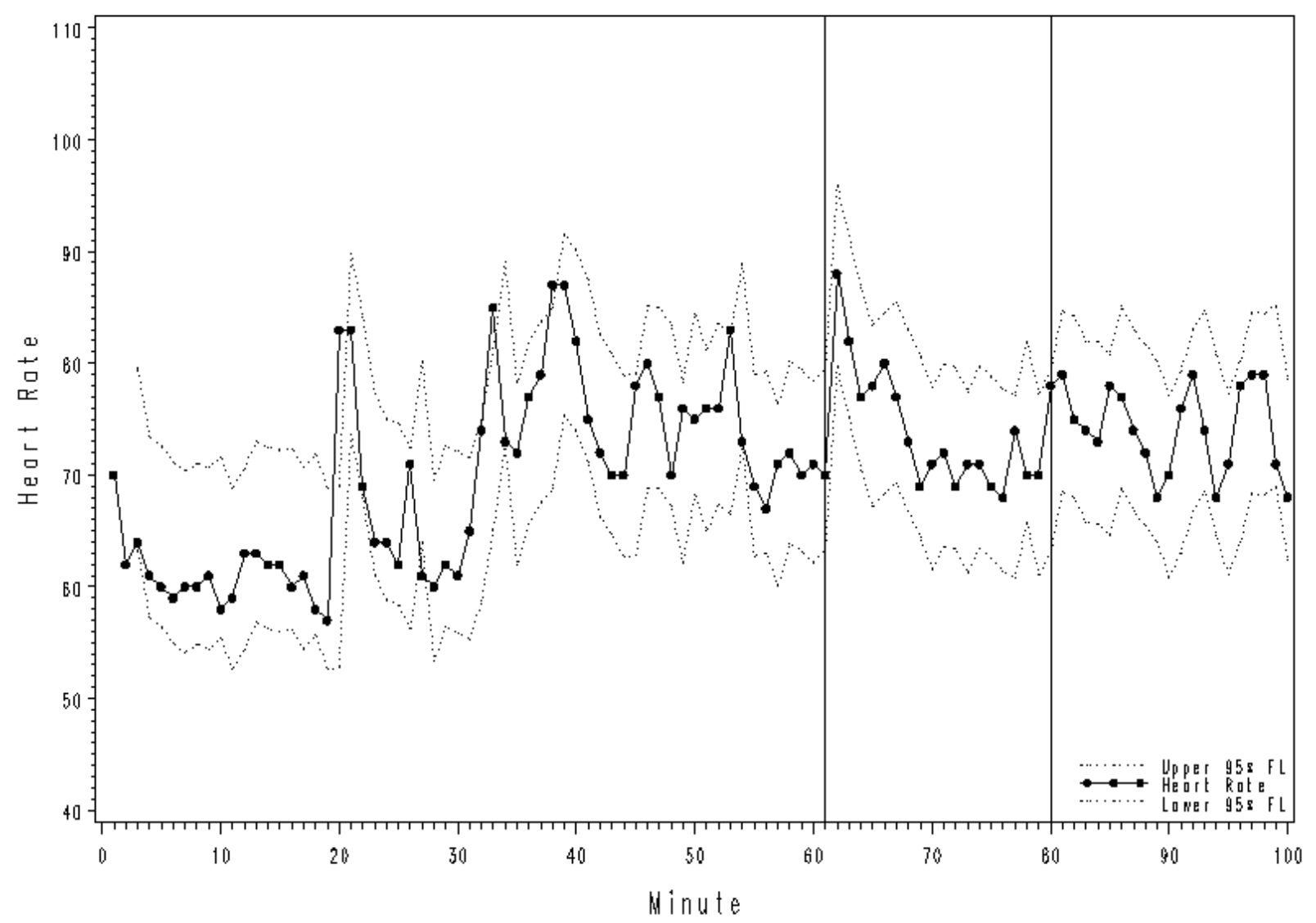

13 Fig. 4. Heart rate (HR) timeplot of the first hundred observations for programmed cuing event 14 period A3 for cow 4127 between 1534 hrs and 1853 hrs on 21 March, 2003. Vertical axis is HR 15 in beats per minute (bpm), horizontal axis is time in minutes, beginning at 1534 hrs. The first 16 vertical line at minute 61 (1634 hrs) represents the first cuing event (1). The second vertical line 17 at minute 80 (1653 hrs) represents the second cuing event (2). Dotted lines represent 95\% lower 18 and upper forecast limits based on the fitted intervention model. 


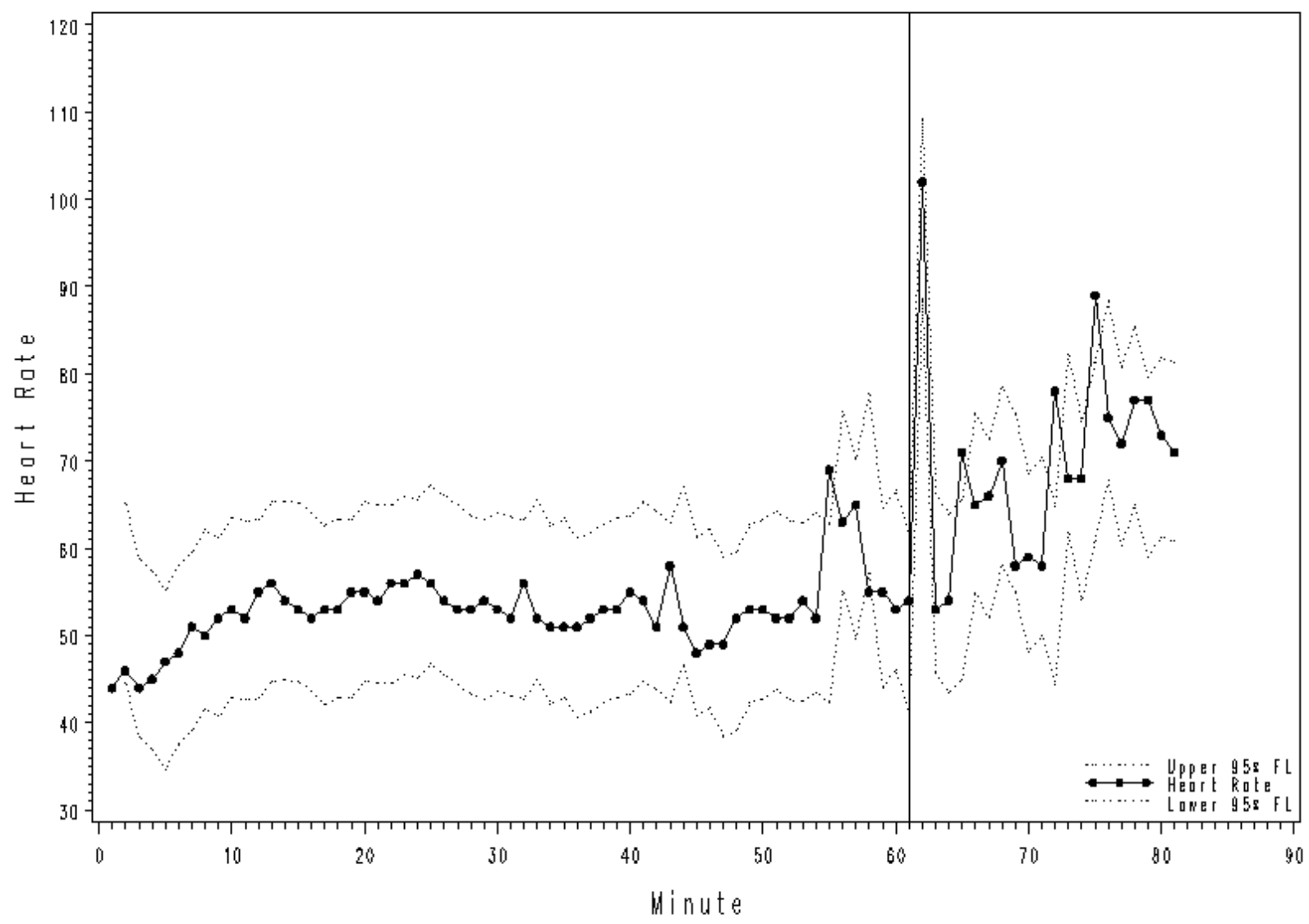

25 Fig. 5. Heart rate (HR) timeplot for a non-programmed cue for period E2 for cow 4130 between 261510 hrs and 1630 hrs on 23 March, 2003. Vertical axis is HR in beats per minute (bpm), 27 horizontal axis is time in minutes, beginning at 1510 hrs. The vertical line at minute 61 (1610 28 hrs) represents the non-programmed environmental / physiological cuing event (NP). Dotted 29 lines represent 95\% lower and upper forecast limits based on the fitted intervention model. 